\title{
Drop size characteristics of forward angled injectors in subsonic cross flows
}

\author{
Venkat S lyengar \\ Propulsion Division,CSIR-NAL \\ Bangalore, Karnataka, India
}

\author{
Srinivas Jangam \\ Propulsion Division, CSIR-NAL \\ Bangalore, Karnataka, India
}

\author{
Sathiyamoorthy Kumarasamy \\ Propulsion Division, CSIR-NAL \\ Bangalore, Karnataka, India
}

\author{
Manjunath Pulumathi \\ Propulsion Division, CSIR-NAL \\ Bangalore, Karnataka India
}

\begin{abstract}
Cross flow fuel injection is a widely used approach for injecting liquid fuel in gas turbine combustors and afterburners due to the higher penetration and rapid mixing of fuel and the cross flowing airstream. Because of the very limited residence time available in these combustors it is essential to ensure that smaller drop sizes are generated within a short axial distance from the injector in order to promote effective mixing. This requirement calls for detailed investigations into spray characteristics of different injector configurations in a crossflow environment for identifying promising configurations. The drop size characteristics of a liquid jet issuing from a forward angled injector into a cross-flow of air were investigated experimentally at conditions relevant to gas turbine afterburners. A rig was designed and fabricated to investigate the injection of liquid jet in subsonic cross-flow with a rectangular test section of cross section measuring 50 $\mathrm{mm}$ by $70 \mathrm{~mm}$. Experiments were done with a 10 degree forward angled $0.8 \mathrm{~mm}$ diameter plain orifice nozzle which was flush mounted on the bottom plate of test section. Laser diffraction using Malvern Spraytec particle analyzer was used to measure drops size and distributions in the near field of the spray. Measurements were performed at a distance of $70 \mathrm{~mm}$ from the injector at various locations along the height of the spray plume for a reasonable range of liquid flow rates as in practical devices.
\end{abstract}

The sprays were characterized using the non dimensional parameters such as the Weber number and the momentum flux ratio and drop sizes were measured at three locations along the height of the spray from the bottom wall. The momentum flux ratio was varied from 5 to 25 . Results indicate that with increase in momentum flux ratio the SMD reduced at the specific locations and an higher overall SMD was observed as one goes from the bottom to the top of the spray plume. This was accompanied by a narrowing of the drop size distribution

\section{INTRODUCTION}

Rapid and efficient fuel air mixing is an important requirement in many propulsion applications particularly in High speed propulsion. Understanding the factors controlling the distribution of specific quantities of atomized fuel to desired locations in the combustor cross section is a key requirement for making improvements in combustion stability, efficiency and control of emissions. Injection of liquid fuel in cross-flow is a promising approach due its potential for rapid atomization and controlled fuel placement. The fuel/liquid plume as a result of its cross-flow interaction can be characterized by a variety of parameters like penetration, spray width, drop size, droplet velocity etc. Over the years, extensive database for jet penetration (covering various liquid and flow parameters) has been generated through the numerous investigations carried out in this field. 
Becker and Hassa [1], from their experiments on subsonic cross-flows $(50-100 \mathrm{~m} / \mathrm{s})$ at elevated pressure, reasoned that the larger particles, by virtue of possessing higher momentum, longer velocity relaxation time and higher inertia, penetrate farther into the air stream. It was also established that the SMD at elevated pressure cross-flows depended on the dynamic pressure of the cross-flow and was independent of $\mathrm{J}$.

Wu et al. [2,3] conducted experiments in subsonic cross-flows (0.2 M, 0.3 M, 0.4M) and noted that smaller droplets were observed near the bottom wall. These droplets are generated from surface breakup and stripped away from the periphery of the liquid column by aerodynamic forces. Tambe et al [4]conducted experimental studies on the behavior of liquid jets injected transversely into a subsonic cross-flow of air. They used three injection liquids, water, Jet-A and n-Heptane, and two injection diameters of 0.381 and $0.762 \mathrm{~mm}$. Measurements were done using Pulsed shadowgraphy and Phase Doppler and Particle Analyzer (PDPA). The behavior of the jet column, the post-breakup spray, as well as the penetration and breakup were studied. They concluded that droplet size decreases with an increase in the cross-flow velocity while penetration increases with an increase in injector diameter or momentum ratio. They also observed that droplet size exhibits a maximum in the spray core for low momentum ratios and near the periphery for high momentum ratios. Lin et al [5] experimentally studied the structures of aerated-liquid jets injected into subsonic cross-flows. They used an aerated-liquid injector with a diameter of $0.5 \mathrm{~mm}$ at freestream Mach numbers of 0.2 and 0.3 and observed that the liquid mass flow rate did not have a significant effect on the drop sizes.

Inamura and Nagai [6] investigated the spray characteristics of a liquid jet in a subsonic airstream using PDPA and measured dropsize distributions and velocities for a liquid jet. Oda et al [7] from their experimental studies at subsonic flows concluded that the mass flow rate increases along the spray height and decreases again after reaching a maximum whereas the SMD only shows an increase in spray height and does not decrease above the maximum mass flow rate location in the spray. Kihm et al. [8] noted that at low subsonic cross-flow speeds, the peak of the SMD size distribution shifted to larger values as the distance from the injector wall was increased. Surya Prakash et al [9] studied sprays in cross-flow Mach numbers between 0.1 and 0.3 and examined drop sizes at various locations along and across the spray.

Tam et al. [10] noted in their review paper that the droplet size distribution within the spray was non-uniform. The droplets were found to be concentrated in a small area of the plume. For cases with high jet/air momentum flux ratio, larger droplets are found in the upper portion of the spray plume while for cases with low jet/air momentum ratio, larger droplets are found predominantly in the spray core.

Investigations on angled injection in subsonic cross-flows have been extremely scarce. Fuller et al [11] studied the effects of injection angle on the breakup process of liquid jets in subsonic cross-flows. Their focus was on the macroscale aspects regarding column trajectories, column fracture location and near field characteristics of the spray.

Costa et al $[12,13]$ examined spray characteristics of angled liquid injection in subsonic cross-flows using water as the test liquid with varying injection angles which were varied from 30 to 90 . They examined overall jet penetration , breakup length and atomization quality and found that injection angles had a greater effect of the atomization quality than liquid to air momentum flux ratios.

In summary it can be seen that while several studies have been done on liquid injection in subsonic cross-flows there is a scarcity of information concerning liquid injection from angled injectors and their drop size and distribution along and across the plume for such sprays in moderately high subsonic conditions which is of interest in afterburners and liquid fuelled ramjets. Furthermore all the studies on angled injection have focused on backward injection, ie along the direction of the cross-flow. In this study a 10 degree forward angled injector is considered to explore the possibility of achieving finer atomization quality at shorter axial distances from the injector location.

\section{NOMENCLATURE}

\begin{tabular}{|c|c|}
\hline $\mathrm{D}_{\mathrm{V} 0.1}$ & $\begin{array}{l}\text { Drop diameter such that } 10 \% \text { of total } \\
\text { liquid volume is in drops of smaller } \\
\text { diameter }\end{array}$ \\
\hline $\mathrm{D}_{\mathrm{v} 0.5}$ & $\begin{array}{l}\text { Drop diameter such that } 50 \% \text { of total } \\
\text { liquid volume is in drops of smaller } \\
\text { diameter }\end{array}$ \\
\hline $\mathrm{D}_{\mathrm{v} 0.9}$ & $\begin{array}{l}\text { Drop diameter such that } 90 \% \text { of total } \\
\text { liquid volume is in drops of smaller } \\
\text { diameter }\end{array}$ \\
\hline SMD & Sauter Mean diameter \\
\hline $\mathrm{d}$ & Orifice diameter \\
\hline $\mathrm{u}$ & Airstream velocity \\
\hline $\mathrm{T}$ & Temperature \\
\hline $\mathrm{J}$ & Momentum flux ratio $J=\frac{\rho_{l} u_{l}^{2}}{\rho_{a} u_{a}^{2}}$ \\
\hline We & Weber Number $W e=\frac{\rho_{a} u_{a}^{2} d}{\sigma}$ \\
\hline
\end{tabular}




$\begin{array}{ll}\rho & \text { Density } \\ \sigma & \text { Surface Tension }\end{array}$

Subscripts

1 liquid

a air

\section{EXPERIMENTAL METHODS}

\section{a. TEST RIG DETAILS}

The experiments were carried out at the Combustion and Gas dynamics laboratory at NAL. A 6" air supply line receives air from a huge central 10 bar storage reservoir. Downstream of the supply line is a rig which is designed and fabricated to investigate the injection of liquid jet in subsonic cross-flow. The 6" diameter is transitioned to a rectangular cross section using a carefully designed transition section $1200 \mathrm{~mm}$ long. The test section has a rectangular cross section of $50 \mathrm{~mm} \times 70$ $\mathrm{mm}$ and is $200 \mathrm{~mm}$ long. Two quartz windows about $3 \mathrm{~mm}$ thick are provided, one on each side for optical access. The windows are flush mounted with the test chamber's flow surface. The fuel injector is mounted at the bottom of the test section about $80 \mathrm{~mm}$ downstream of the nozzle exit and is flush with the bottom wall of the test section. Two pressure transducers are used to measure the total and static pressures and to estimate the Mach number. One pressure transducer $(0$ 10 bar g with an accuracy of $0.2 \%$ FS) was placed far upstream in the rig to measure the total pressure and the second pressure transducer $(0-115$ psia with an accuracy of $0.1 \%$ BFSL) was used to measure the static pressure after the nozzle exit at the entrance to the test section. Two sturdy clamped supports are provided to support the rig and arrest vibration during the test. A steady run time of 15-25 seconds for each test at various desired air flow rates corresponding to different fuel flow rates is available for experimental measurements.

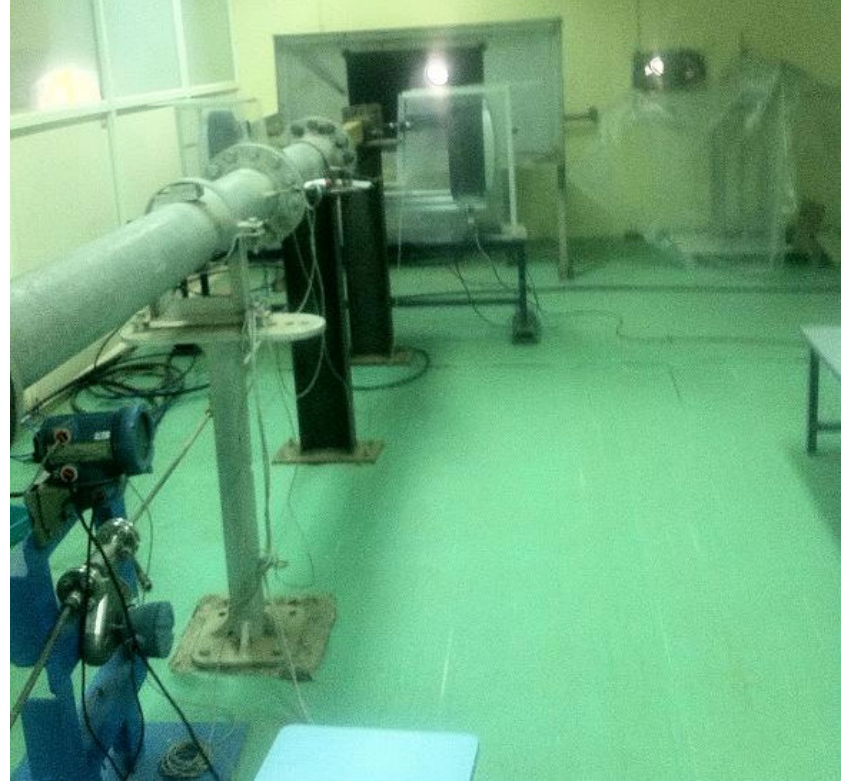

Fig 1: Test rig used for the spray characterization studies

\section{b. LIQUID FUEL INJECTION SETUP}

A 10 degree angled fuel injector of $0.8 \mathrm{~mm}$ exit diameter as shown in Fig 3 is used in this study. A mounting bracket is used to attach the fuel injectors to the bottom part of the test section. The liquid is stored in small high pressure tank and pressurized with air for supplying it at the desired flow rate. A Coriolis flow meter (Micro motion CMF-010M with a 1700 Transmitter) is used to monitor and measure the liquid fuel flow rate. The liquid is passed through a filter before being injected into the flow. A pressure sensor UNIK 5000 system (0- $700 \mathrm{psig})$ is used to $\log$ and monitor the injection pressure.

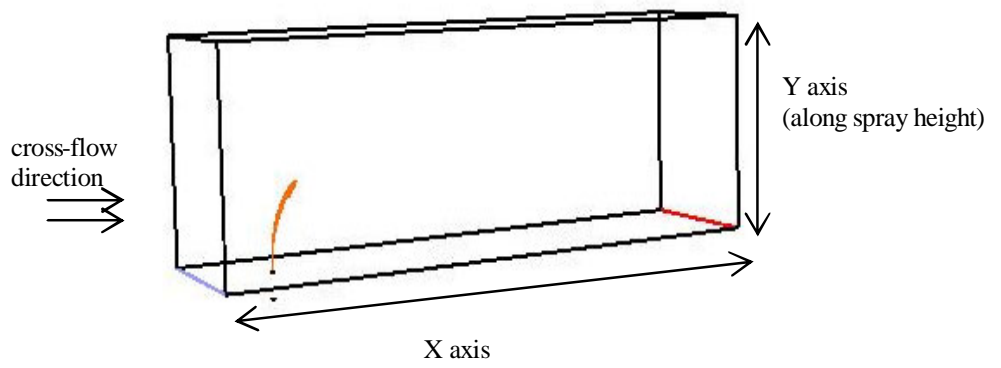

Fig 2: Schematic of the Liquid jet in cross flow configuration. 

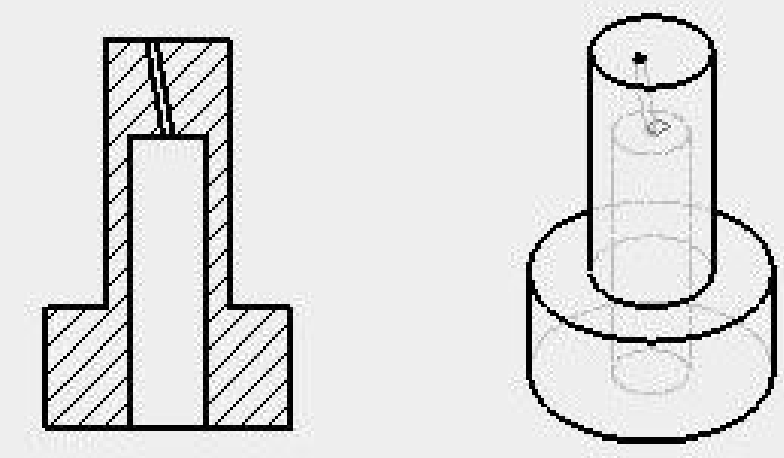

Fig 3: Injector used for the spray studies

\section{c. DROP SIZE AND DISTRIBUTION MESUREMENTS}

A Malvern Spraytec particle analyzer is used for the drop size and distribution measurements. This model is a widely used commercially available particle size analyzer and uses a low power $\mathrm{He}-\mathrm{Ne}$ laser $(5 \mathrm{~mW})$ which is expanded to $10 \mathrm{~mm}$ diameter beam for interrogating the spray. Experiments were done with a $300 \mathrm{~mm}$ Fourier lens. This instrument along with the rig set up, provides the data regarding the drop size distribution in the volume of intersection of the circular beam and the spray in cross-flow. The set up is such that the beam passes perpendicular to the airflow and parallel to the bottom surface. Arrangement is made such that the spray is interrogated at a few points from the inner to the outer boundary of the spray at a fixed axial distance.

\section{RESULTS AND DISCUSSION}

The non-dimensional parameters Weber number(We) and momentum flux ratio $(J)$ were used to characterize the sprays. The various tests performed yielded $\mathrm{J}$ ratios in the range of 10 to 25 for a Weber number of 240 corresponding to a mach number of 0.4

Drop size distribution measurements were performed at a distance of $70 \mathrm{~mm}$ from the injector and at 3 locations along the height of the spray by moving from the bottom towards the top of the spray. The measured drop sizes range was divided into 60 intervals in the logarithmic scale.

Figure 4 shows the variation of SMD along the spray height for different values of momentum flux ratio. It is seen that the SMD of the droplets progressively increases from the inner boundary to the outer boundary for any given $\mathrm{J}$ ratio and Weber number. This is consistent with the fact that larger droplets penetrate further into the airstream and thus progressively contribute towards a higher SMD as the upper boundary of the spray is approached. However as the $\mathbf{J}$ ratio is increased, the SMD values show a progressive reduction, and the range of SMD values across the spray becomes smaller. This is evident from Fig 5 where the span of the spray is plotted at various heights.

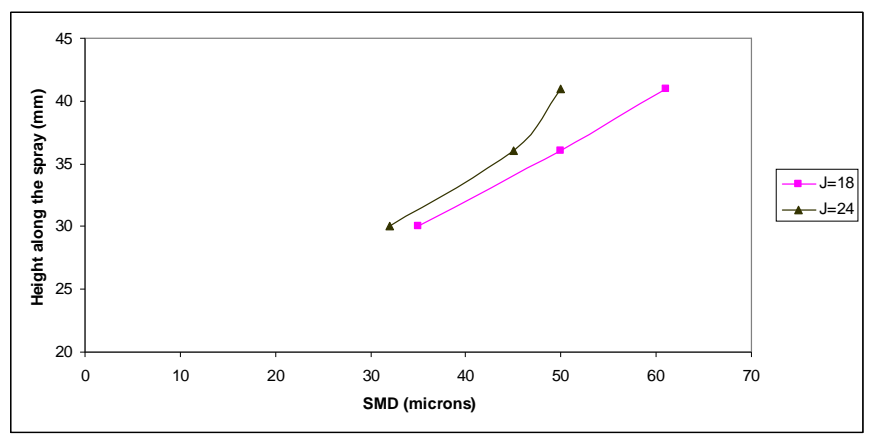

Fig 4: SMD variation along spray height for two different $\mathrm{J}$ ratios

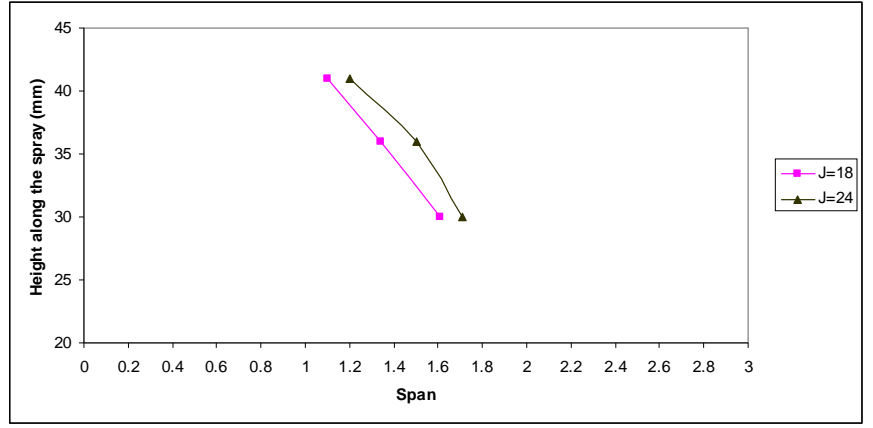

Fig 5: Span variation along spray height for two different $\mathrm{J}$ ratios

The relative span factor is defined by

$$
\nabla_{V}=\frac{D_{V 0.9}-D_{V 0.1}}{D_{V 0.5}}
$$

where Dv0.1, Dv0.5 and Dv0.9 are the classical representative diameters of the volume-based drop size distribution. The span is good measure regarding the width of the distribution.An interesting trend is that at lower $\mathrm{J}$ ratios a more uniform drop size distribution is seen at all locations of the spray. Fig 6-8 show the spray drop size distribution for three different heights from the injector base $(30,36$ and $41 \mathrm{~mm})$ at $x=70 \mathrm{~mm}$ downstream for a Weber number of 240 and momentum flux ratios of $13,18,22$. The $\mathrm{x}$ axis shows the drop size in the logarithmic scale. 


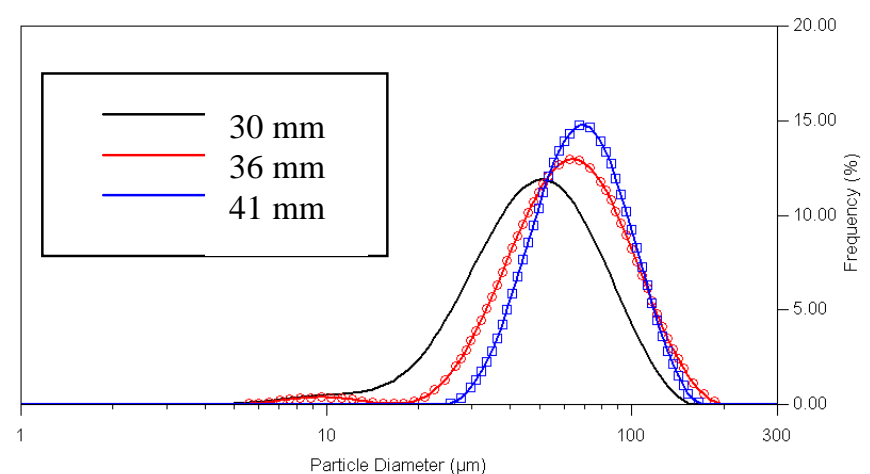

the spray height for $\mathrm{J}=13$

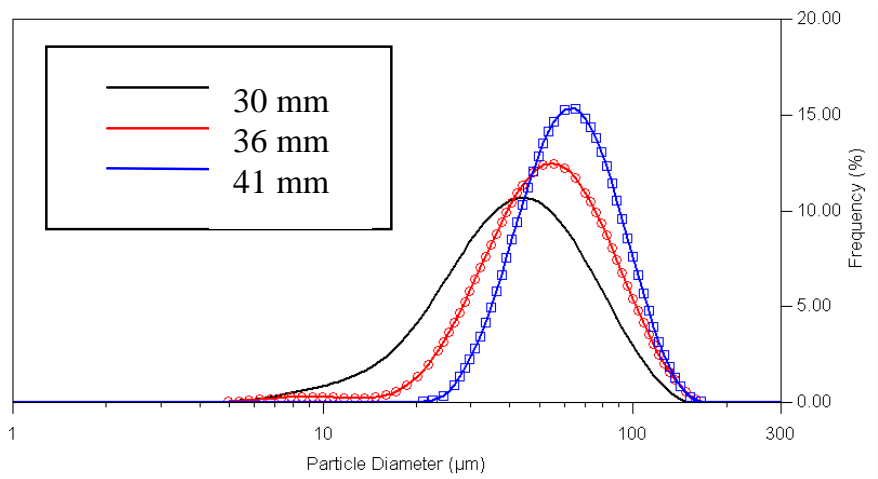

Fig 7: Drop size distribution at three different locations along the spray height for $\mathrm{J}=18$

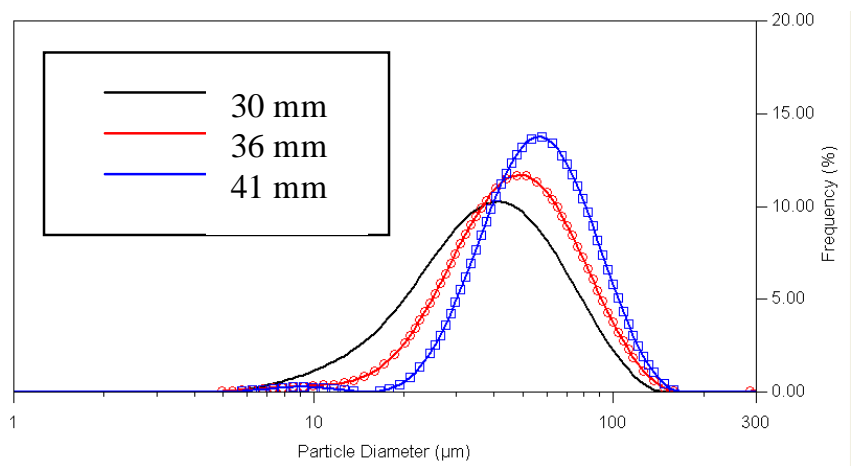

Fig 8: Drop size distribution at three different locations along the spray height for $\mathrm{J}=22$

It is clearly seen that the drop size distribution across the spray plume is non uniform. It is also seen that as the measurement location is moved towards the top of the spray, the peak of the size distribution shifts to a larger diameter and the width of the distribution becomes narrower. A longer tail is prominent for the shortest height from the bottom $(30 \mathrm{~mm})$ in all the cases. These smaller droplets observed near the bottom wall are generated by surface breakup mechanism with droplets getting stripped away from the periphery of the column due to aerodynamic forces

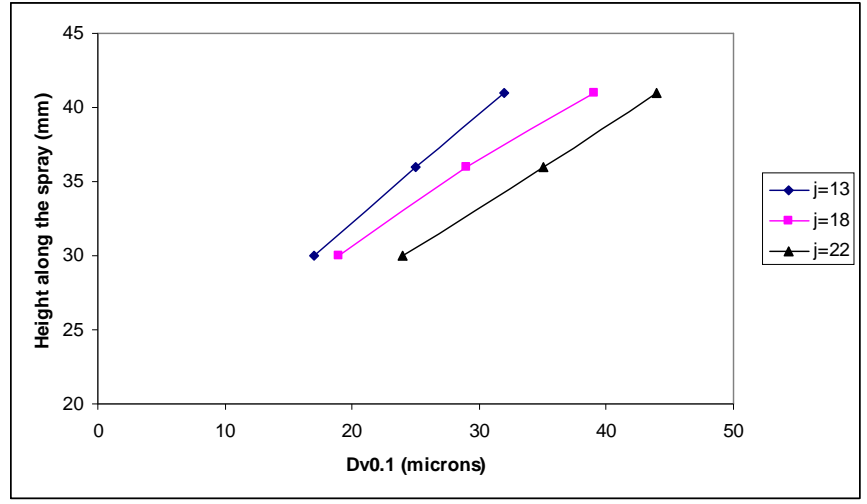

Fig 9: Distribution of Dv0.1 at three different locations along the spray height for various $\mathrm{J}$ ratios

Fig 9 shows the variation of Dv0.1 which is the drop diameter such that $10 \%$ of the total volume of drops is in drops of smaller diameter. It is clearly seen that the lowest value of Dv0.1 is achieved for the maximum momentum flux ratio case at the lowest height signifying a significant presence of smaller drops under these conditions. These kind of information can be very useful since as pointed out by Lefebvre, in some applications, the ignition source is placed near the bottom wall and a large number of smaller drops at the lower leeward surface will be beneficial for fast ignition with the larger drops in the upper portion providing better penetration into the airstream.

\section{CONCLUSION}

The jet issuing out from a forward angled injector in a high speed cross-flow environment was partially characterized at a distance of $70 \mathrm{~mm}$ from the injector. This was done by examining the droplet size distribution, span factor and volume concentration across the spray plume at that particular axial location near the injector using a Malvern Spraytec instrument. It is seen that as one goes from the bottom to the top of the spray plume, the drop size distribution becomes narrower. The droplet volume concentration is significantly redistributed across the spray plume with increasing jet to air momentum flux ratios along with the increasing spray plume size

\section{ACKNOWLEDGMENTS}

This work was supported by a CSIR grant through a Supra Institutional Project (SIP-PR-02) which is gratefully acknowledged. The authors wish to thank Muralidhara H S 
,Muthuselvan G and Vinod Kumar Vyas of the Combustion and Gas Dynamics lab, Propulsion Division for their support in doing the experiments. The authors wish to thank Director, CSIR-NAL and Head, Propulsion Division for their encouragement and support.

\section{REFERENCES}

1. Becker, J., and Hassa, C.,(2002) "Breakup and Atomization of a Kerosene Jet in Crossflow at Elevated Pressure," Atomization and Sprays, Vol. 11, pp. 49-67.

2. Wu, P., Kirkendall K.A., Fuller R.P., Nejad A.S.,(1997) "Breakup process of liquid jets in subsonic crossflows," JPP 13 (1), pp 64-73.

3.Wu, P., Kirkendall K.A., Fuller R.P., Nejad A.S.,(1998) "Spray structures of liquid jets atomized in subsonic crossflows," JPP 14 (2) , pp 173-182.

4. Lin, K.C., Kennedy ,P.J., and Jackson T.A.,(2002) "Structures of aerated liquid jets in high speed crossflows" AIAA 2002-3178.

5.Tambe, S. B., Jeng, S. M., Mongia, H., and Hsiao, G., (2005) "Liquid Jets in Subsonic Crossflow," AIAA 2005-731.

6. Inamura, T., and Nagai, N., (1997)" Spray characteristics of liquid jets traversing subsonic airstreams" JPP 13 (2),

pp 250-256.

7. Oda, T., Hiroyasu, H., Nishida, K., and Arai, M., (1994) "Characterization of liquid jet atomization across a high-speed airstream" JSME International Journal, Series B: Fluids \& Thermal Engineering 37(4): pp 937-944.

8. Kihm, K. D., Lyn, G. M., and Son, S. Y.,(1995) "Atomization of Cross-Injecting Sprays into Convective Air Stream," Atomization and Sprays, Vol. 5, 1995, pp. 417-433.

9. Surya Prakash, R., and Raghunandan, B. N.,(2011) "Spray in Cross Flow: Study on Mass Flow Distribution" AIAA 20115949.

10. Tam, C. J., Stouffer, C. S., Lin, K.C., Gruber M., and Jackson, T.,(2005) "Gaseous and liquid injection into high speed cross flows". AIAA 2005-0301.
11.Fuller, R.P., Wu, P.K., Kirkendall, K.A., Nejad, A.S., (2000). Effects of Injection Angle on Atomization of Liquid Jets in Transverse Airflow. AIAA Journal, Vol 38, 64-72.

12 .Costa, M., Melo, M. J., Sousa, M. M., and Levy, Y., (2006) "Spray Characteristics of Angled Liquid Injection into Subsonic Crossflow," AIAA Journal, Vol. 44, No. 3, pp. 646653.

13.H. Almeida., J. M. M. Sousa., and M. Costa., (2010) "Effect of the Liquid Injection Angle on the Atomization of Liquid Jets in Subsonic Crossflows" 23rd Annual Conference on Liquid Atomization and Spray Systems, Brno, Czech Republic, September 2010. 